\title{
RESEARCH
}

\section{Experience of Surfactant Therapy and Outcome in Preterm neonates with Respiratory Distress Syndrome}

\author{
B.K Ganesh ${ }^{* 1}$ Adhikari Sudhir ${ }^{1}$, Gauchan Eva ${ }^{1}$ \\ ${ }^{1}$ Department of Pediatrics, Manipal College of Medical Sciences, Pokhara-11, Nepal
}

Date of Submission: Feb 27, 2019

Received in Revised Form: March 20, 2019

Date of Acceptance: April 23, 2019

Date of Publishing: July 30, 2019

\begin{abstract}
Background:

To share the experience and assess the outcome in preterm babies receiving surfactant as prophylactic and rescue therapy.
\end{abstract}

\section{Methods:}

Prospective hospital based observa-tional study conducted in the Neonatal intensive care unit of Manipal Teaching Hospital, Pokhara Nepal, and study period was from 1st January 2015 to 31 st December 2017. Surfactant was administered to preterm babies less than 37 weeks with the diagnosis of respiratory distress syndrome.

\section{Results:}

A total of 40 newborns received surfactant of which 19 neonates received prophylactic whereas 21 received rescue therapy .The mean gestation (weeks) was $30.68 \pm 1.974$ in prophylactic and $32 \pm 2.168$ in rescue therapy groups. Mean Birth weight in prophylactic group was 1302.26 \pm 253.15 grams and $1455.24 \pm 344$ grams in rescue group. Complications of surfactant administration were noted in $25(62.5 \%)$ neonates. Desaturation $13(52 \%)$ and bradycardia 5(20\%) were common complications during surfactant administration. Mean hospital stay was $14.26 \pm 7.56$ (days) in prophylactic and $12.52 \pm 7.16$ (days) in rescue groups ( $\mathrm{p}$ value $0.46)$. Difference in duration of continuous positive airway pressure, ventilations, oxygen, requirement of inotropes were also not statically significant.

\section{Conclusions:}

Rescue surfactant therapy was found to be as effective as prophylactic therapy in preterm babies with respiratory distress syndrome.

Key words: Hyaline membrane disease, Newbornm, Pulmonary Surfactants.

*Corresponding author: Dr Ganesh B. K., Department of Pediatrics, Manipal College of Medical Sciences, Pokhara-11, Nepal Email ID: ganesh3bk@yahoo.com.

\section{INTRODUCTION}

Respiratory distress syndrome (RDS) is an important cause of morbidity and mortality in newborn infants especially those born prematurely. ${ }^{1}$ Surfactant replacement has been established as an effective and safe treatment modality in premature neonates since early 1990 s. $^{2}$ Surfactant administration improves respiratory status, decreases ventilator requirement, hospital stay and over all outcome. Subsequent trials have indicated that prophylactic or early administration of surfactant resulted in fewer pneumothoraces, less pulmonary interstitial emphysema and improved survival without bronchopulmonarydysplasia (BPD) ${ }^{3-5}$ However, other recent studies have found the 
benefit of prophylactic surfactant is no longer evident in group of infants when continuous positive airway pressure (CPAP) is used routinely.

There is limited information about experience of surfactant use in our part of the world. The study aims to share the experience and outcome of surfactant in preterm babies and to know the advantages of prophylactic over rescue therapy in RDS.

\section{MATERIALS AND METHODS}

This study was a prospective hospital based observational study conducted in the neonatal intensive care unit (NICU) of Manipal Teaching Hospital, Pokhara, Nepal which is a 22 bedded NICU with three ventilators and four continuous positive airway pressure (CPAP) machines. The study period was from $1^{\text {st }}$ January 2015 to $31^{\text {st }}$ December 2017. All the neonates less than 37 weeks who received surfactant during the study period were eligible for the study. Newborns with major congenital anomalies, hemodynamically unstable neonates and parental refusal for the administration of surfactant were excluded from the study.

Bovine surfactant was administered to preterm neonates less than 37 weeks with the diagnosis of RDS. Diagnosis of RDS was established on the basis of clinical features along with chest radiography. Surfactant was administered in two or four divided doses through nasogastric tube after endotracheal intubation. Neonate was put on supine, right lateral and left lateral position with slight head elevation after that bag and mask ventilation was given to spread surfactant over alveoli. Dose of administration was $4 \mathrm{ml} / \mathrm{kg}$ body weight. Prophylactic use is indicated in neonates less than 32 weeks and as soon as birth till 6hours of life and rescue therapy for all neonates with the diagnosis of RDS up to the 72 hours of life.

Approval for the research was obtained from the institutional review committee (IRC) of Manipal Teaching Hospital. Written consent was taken from the parents prior to the commencement of the study. Demographic parameters and maternal details were recorded in a preformed Performa. Timing of surfactant administration in hours, duration of oxygen administration, CPAP and ventilator support and duration of hospital stay were also recorded. Administration of prophylactic as well as rescue therapy was recorded. Complications of surfactant adminis-tration and final outcome i.e. discharge; death, referral and left against medical advice were noted. Data analysis was done using SPSS version 16 . Continuous data was recorded as mean \pm S.D. and categorical variables as number and percentage. Chi square and independent ' $t$ ' test were used as appropriate. Level of significance was taken as 0.05 .

\section{RESULTS}

Out of 40 newborns who met our inclusion criteria, 19 neonates received prophylactic therapy whereas 21 received rescue therapy. The mean gestation (weeks) was $30.68 \pm 1.974$ in prophylactic and $32 \pm 2.168$ in rescue group. There was no statistical difference in between the group ( $\mathrm{p}$ value - 0.217). Mean birth weight in prophylactic group was $1302.26 \pm 253.15$ grams and $1455.24 \pm 344.636$ in rescue group ( $\mathrm{p}$ value 0.520 ) as shown on Table 1.

Out of 40 neonates only 17 preterm mothers received antenatal steroid therapy to prevent hyaline membrane disease. On prophylactic $10(52.63 \%)$ and rescue $7(33.33 \%)$ neonate mother received steroid that's also not significant. Regarding the hospital stay it was 2 days higher in prophylactic as compared to rescue as mean hospital stay was $14.26 \pm 7.56$ (days) in prophylactic and $12.52 \pm 7.16$ (days)in rescue group (p-0.46) since premature and low birth babies were more included in prophylactic group.

Table 1: Demographics characteristics of enrolled newborns

\begin{tabular}{|l|l|l|l|}
\hline & \multicolumn{1}{|c|}{$\begin{array}{c}\text { Prophylactic } \\
\mathrm{n}(\%)\end{array}$} & \multicolumn{1}{|c|}{ Rescue n(\%) } & P value \\
\hline Number (\%) & $19(47.5 \%)$ & $21(52.5 \%)$ & \\
\hline Sex & & & \\
\hline Male & $11(57.89 \%)$ & $12(57.1 \%)$ & 0.962 \\
\hline Female & $8(42.10 \%)$ & $9(42.85 \%)$ & \\
\hline Gestation(Weeks) & $30.68 \pm 1.974$ & $32 \pm 2.168$ & 0.217 \\
\hline $\begin{array}{l}\text { Birth } \\
\text { weight(Grams) }\end{array}$ & $1302.26 \pm 253.151$ & $1455.24 \pm 344.636$ & 0.520 \\
\hline Apgar 1 min & $6 \pm 1.247$ & $5.81 \pm 1.778$ & 0.535 \\
\hline Apgar 5 min & $7.63 \pm 1.116$ & $7.86 \pm 1.424$ & 0.258 \\
\hline Antenatal steroid & $10(52.63 \%)$ & $7(33.33 \%)$ & 0.218 \\
\hline $\begin{array}{l}\text { Antepartum } \\
\text { Hemorrhage }\end{array}$ & 0 & 3 & $\mathrm{~F}(0.043)$ \\
\hline Eclampsia & $7(36.84 \%)$ & $2(9.52 \%)$ & 0.039 \\
\hline PROM & $5(26.31 \%)$ & $5(23.80 \%)$ & 0.885 \\
\hline
\end{tabular}


Mean duration of ventilation and oxygen was also not statistically significant in this group.

Table 2: Outcome variables in prophylactic and rescue therapy groups

\begin{tabular}{|l|l|l|l|}
\hline & Prophylactic & \multicolumn{1}{|c|}{ Rescue } & P Value \\
\hline Number (\%) & $19(47.5 \%)$ & $21(52.5 \%)$ & \\
\hline $\begin{array}{l}\text { Hospital stay } \\
\text { days }\end{array}$ & $14.26 \pm 7.56$ & $12.52 \pm 7.16$ & 0.46 \\
\hline CPAP days & $3.00 \pm 1.79$ & $3.14 \pm 2.1$ & 0.82 \\
\hline $\begin{array}{l}\text { Ventilation } \\
\text { days }\end{array}$ & $0.89 \pm 1.56$ & $0.57 \pm 9.26$ & 0.425 \\
\hline Oxygen days & $4.58 \pm 2.85$ & $3.95 \pm 2.41$ & 0.457 \\
\hline $\begin{array}{l}\text { Required } \\
\text { inotropes }\end{array}$ & $6(31.6 \%)$ & $4(19.0 \%)$ & 0.381 \\
\hline $\begin{array}{l}\text { Discharged } \\
\text { (Good } \\
\text { outcome) }\end{array}$ & $13(68.4 \%)$ & $11(52.4 \%)$ & 0.301 \\
\hline Bad outcome & $6(31.6 \%)$ & $10(47.6)$ & \\
\hline Complications & $12(63.15 \%)$ & $13(62.0 \%)$ & 0.935 \\
\hline
\end{tabular}

Complications were seen in 25(62.5\%) neonates. $12(48 \%)$ neonates from prophylactic and $13(52 \%)$ from rescue group. Complications included desaturation in $13(52 \%)$, bradycardia $5(20 \%)$, PDA $3(12 \%)$, seizure $3(12 \%)$ and pulmonary hemorrhage in 1(4\%) as shown in Fig. 1

\section{Figure 1: Complications of surfactant admini- stration}

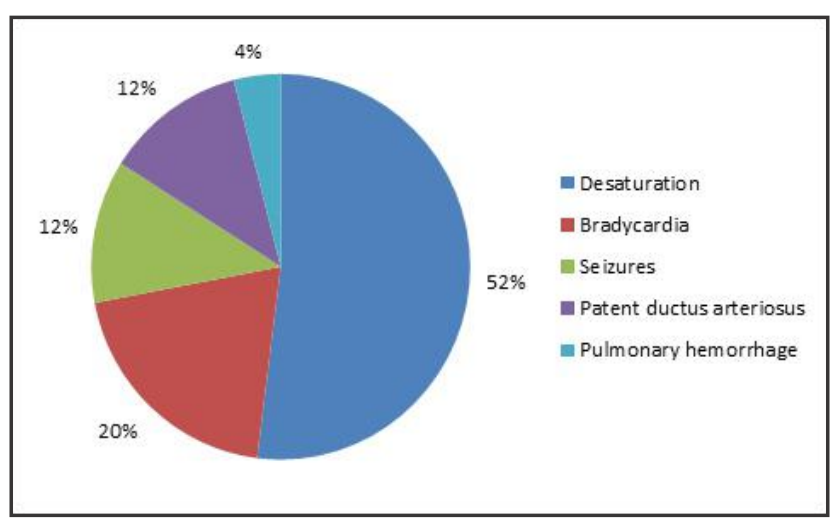

Total neonates discharged in normal condition after the treatment were $24(60 \%)$ of which $13(68.4 \%)$ and $11(52.4 \%)$ were from the prophylactic and rescue therapy respectively $(\mathrm{p}$ value -0.301). Left against medical advice, refer, death were considered as bad outcome which include $6(31.57 \%)$ and $10(47.61 \%)$ in prophylactic and rescue therapy and was no statistical significant. There were $2(5 \%)$ neonates both of which were from rescue group.

\section{DISCUSSION}

World health organization (WHO) has estimated around 1.1 million preterm neonatal deaths every year. ${ }^{7}$ Many clinical trials carried out in the 1980 s and 1990 s to decrease the mortality of preterm babies found surfactant use as one of the strategies to reduce mortality and complication. ${ }^{8,9}$

Randomized controlled trials have shown that surfactant therapy in RDS results in overall $40 \%$ reduction in mortality and $35-50 \%$ reduction in air leak. ${ }^{10-12}$ Few countries like Kuwait, South Africa, India and Iran have reported regarding the benefits of surfactant ${ }^{13-16}$ In our study 34 neonates were put on CPAP out of 40 so early use of CPAP along with surfactant may have reduced morbidity and mortality in neonates which is similar and comparable to others trial from different developed countries. Only 17 received antenatal steroids might be attributed most of the un-booked mothers present in the second stage of labor as well as preterm babies are referred from peripheral centers.

Cochrane review had shown surfactant along with CPAP may have reduced ventilation days and lower mortality in preterm neonates ${ }^{17-19}$ The most common morbidities seen in our study was desaturation accounting for $52.5 \%$. Other complications seen were bradycardia, patent ductus artriosus (PDA), seizure and one (4\%) case of pulmonary hemorrhage. Researchers have shown medical morbidities such as intraventicular hemorrahage (IVH), necroitising enterocolitis(NEC), Patent Ductus Atreriosus (PDA ) has not change with use of surfactant ${ }^{20}$ We have also noted PDA as complications similar to other findings but were unable to note long term complications like Broncho Pulmonary Dysplasia ( BPD) and Retinopathy of Prematurity(ROP).

In our study difference in the overall outcome, duration of CPAP, ventilation, complications, hospital stay between prophylaxis and rescue surfactant group was statistical insignificant which is also similar to other meta-analysis studies (National Institute of child health and Human Development Support Trial and Vermont 
Oxford Network). ${ }^{6,21}$ Mean hospital stay was two days more in prophylactic group compared with rescue group which might be due to enrollment of more premature and less birth weight neonates in prophylactic group.

The mortality was 2 out of 40 neonates which account for $5 \%$ which in contrast to other studies where mortality is higher $(21 \%-80 \%){ }^{22-23}$ This could be as these were babies who got discharged on left against medical advice (LAMA) or were referred to other centers. We couldn't find out the numbers of mortality in those babies. All the NICU, surfactant expenses had to be borne by the patient party so that may be also the factor for LAMA and refusal for further treatment. Antenatal steroid administration has not shown significant in prophylactic and rescue therapy in morbidity which is also similar to other studies ${ }^{24}$ The results have shown that the mortality was very low among study subject and majority of them improved and got discharged. This is similar to the study conducted by Suresh and Soll $(2005)^{25}$ in 23 and 34 weeks gestational aged premature neonates. Sankar et al., $(2016)^{26}$ however found no difference in the risk of mortality in their randomized control trial. Higher mean gestation (weeks) is $30.68 \pm 1.974$ and $32 \pm 2.168$ and birth weightis $1302.26 \pm 253.15 \mathrm{grams}$ and $1455.24 \pm 344.636$ on prophylactic and rescuetherapy respectively which is also one of the factor contributing better outcome.

\section{CONCLUSION}

Our study does not show the added benefit of early administration of surfactant in the prognosis of premature neonates compared with rescue surfactant replacement therapy.

Small sample size, lack of follow up and new borns were not randomized were the potential limitation of our study. In future large scale, prospective and randomized controlled trial studies might be beneficial. Significant cost of surfactant procurement is also the concern for developing countries.

\section{REFERENCES}

1. Kattwinkel J, Robinson M, Bloom BT, Delmore P, Ferguson JE. Technique for intrapartum administration of surfactant without requirement for an endotracheal tube. J Perinatol. 2004;24:360-5.

2. Engle WA; American Academy of Pediatrics Committee on Fetus and
Newborn. Surfactant replacement therapy for respiratory distress in the preterm and term neonate. Pediatrics.

2008;121(2):419-432.

3. Soll RF. Synthetic surfactant for respiratory distress syndrome in preterm infants. Cochrane Database Syst Rev. 2000;(2):CD001149.

4. Seger N, Soll R. Animal derived surfactant extract for treatment of respiratory distress syndrome. Cochrane Database Systb Rev. 2009; (2):CD 007836.

5. Soll RF, Blanco F. Natural surfactant extract versus synthetic surfactant for neonatalrespiratory distress syndrome. Cochrane Database Syst Rev. 2001;(2): CD000144.

6. Rojas-Reyes MX, Morley CJ, Soll R. Prophylactic versus selective use of surfactantin preventing morbidity and mortality in preterm infants. Cochrane Database Syst Rev. 2012;3(3):CD00 0510 .

7. March of Dimes, PMNCH, Save the Children, WHO. Born Too Soon: The Global Action Report on Preterm Birth. Eds CP Howson, MV Kinney, JE Lawn. World Health Organization. Geneva, 2012.

8. Schwartz RM, Luby AM, Scanlon JW, Kellogg RJ. Effect of surfactant on morbidity, mortality, and resource use in newborn infants weighting 500 to $1500 \mathrm{~g}$. New England Journal of Medicine. 1944;330:1476-80.

9. Jeffrey A, Timothy E. Hydrophobic Surfactant Proteins in Lung Function and Disease. New England Journal of Medicine. 2002;347:2141-8.

10. Halliday HL. Surfactants: past, present and future. J Perinatol. 2008; 28: S47-56.

11. Soll RF. Synthetic surfactant for respiratory distress syndrome in preterm infants. Cochrane Database Syst Rev. 2003; 3: CD001149.

12. Seger N, Soll R. Animal-derived surfactant extract for treatment of respiratory distress syndrome. Cochrane Database Syst Rev. 2009; 2: CD007836.

13. Victorin LH, Deverajan LV, Curstedt T, 
Robertson B. Surfactant replacement in spontaneously breathing babies with hyaline membrane disease - a pilot study. Biol Neonate. 1990; 58: 121-6.

14. Cooper PA, Saloojee H, Bolton KD, MokhachaneM. Survival of low birth weight infants at Baragwanath Hospital, 1950-1996. S Afr Med J. 1999; 89: 117981.

15. Narang A, Kumar P, Dutta S, Kumar R. Surfactant therapy forhyaline membrane disease: the Chandigarh experience. Indian Pediatr. 2001; 38: 640-6.

16. Gharebhaghi MM, Sakha SHP, Ghajazadeh M, Firoozi E. Complications among premature neonates treatedwith Beractant and Poractantalfa. Indian J Pediatr. 2010; 77: 751-4.

17. The SUPPORT Study Group of NICHD: Early CPAP versus surfactant in extreme preterm infants. N Engl J Med. 2010; 362: 1970-9.

18. Morley CJ, Davis PG, Doyle LW, Brion LP, Hascoet JM, Carlin JB. COIN Trial Investigators: Nasal CPAP or intubation at birth for very preterm infants. $\mathrm{N}$ Engl $\mathrm{J}$ Med. 2008; 358: 700-8.

19. Stevens TP, Blennow M, Soll RF. Early surfactant administration with brief ventilation vs selective surfactant and continued mechanical ventilation for preterm infants with or at risk for respiratory distress syndrome. Cochrane Database Syst Rev. 2004; (3): Cd0 03063.

20. Philip AG. Neonatal mortality rate: is further improvement possible? J Pediatr. 1995;126(3):427-433.

21. Soll RF, Morley CJ. Prophylactic versus selective use of surfactant in preventingmorbidity and mortality in preterm infants. Cochrane Database Syst Rev. 2001;(2): CD000510.

22. Cooper PA, Saloojee H, Bolton KD, MokhachaneM. Survival of low birthweight infants at Baragwanath Hospital, 1950-1996. S Afr Med J. 1999; 89: 117981.

23. Vidyasagar D, Velaphi S, Bhat VB. Surfactant Replacement Therapy in Developing Countries. Neonatology. 2011; 99: 355-66.
24. National Institutes of Health. Effect of corticosteroids for fetal maturation on perinatal outcomes. NIH Consens Statement. 1994;12(2):1-24.

25. Suresh GK, Soll RF. Overview of surfactant replacement trials. J Perinatol. 2005; 25(suppl 2):S40-S44.

26. Sankar, MJ, Gupta N, Jain K, Agarwal R, and Paul VK. Efficacy and safety of surfactant replacement therapy for preterm neonates with respiratory distress syndrome in low- and middle-income countries: a systematic review. J Perinatol. 2016; 36 Suppl 1: S36-48. 